\title{
Educação Física na escola e a afetividade: a construção do autorrespeito
}

\author{
The Physical Education at school and affectivity: the construction of \\ self-respect
}

\author{
Luana Cristine Franzini de Conti* \\ Universidade Estadual Paulista Júlio de Mesquita Filho \\ Ângela Pereira Teixeira Victória Palma** \\ Universidade Estadual de Londrina
}

Resumo No debate educacional atual, a preocupação com os aspectos afetivos nas aulas tem sido um dos temas recorrentes. Neste artigo, nosso objetivo foi apresentar estudos que explicitam pressupostos teóricos construtivistas em relação ao desenvolvimento da afetividade de estudantes, buscando tecer relaçóes entre eles e suas contribuições na construção da afetividade em aulas de Educaçáo Física. Para tanto, utilizamos como recurso metodológico a pesquisa bibliográfica. Concluímos que pelo ensino de alguns conteúdos da disciplina há várias possibilidades de favorecer o desenvolvimento do autorrespeito, a partir do resgate e problematizaçáo das virtudes morais, a fim de que os alunos tomem consciência das representaçóes que têm de si e do grupo, dos projetos de vida que elegem e possam construir representaçóes nas quais as virtudes morais ocupem um lugar central em sua identidade.

PALAVRAS-CHAVE: Educação Física; Desenvolvimento Moral; Afetividade.

\begin{abstract}
In the current educational debate, the concern about affective aspects in the classroom has been one important issue. The aim of this article was to present studies that explain constructivist theoretical assumptions regarding the development of affection in students, willing to make a link between its relationships and contributions within the construction of affection in Physical Education classes. Methodological resource was used as literature review in this study. We conclude that by teaching some contents of the discipline there are several possibilities of favoring the development of self-respect starting with the recovery and questioning of moral virtues so that students can take consciousness of the representations they have from themselves, their group, and their elected life projects. Therefore, they will be able to build representations in which moral virtue may play a central role in their identity.
\end{abstract}

KEYWORDS: Physical Education; Moral Development; Affectivity. 


\section{Introdução}

A preocupação com as emoçôes, afetos, sentimentos em um projeto educativo que acontece na escola tem sido foco de estudos para educadores e pesquisadores do campo da educação.

Em relaçấo à disciplina Educação Física, a importância da manifestação da afetividade ganha espaço gradativamente, sendo comum encontrarmos estudantes de graduação e professores atuantes que justificam suas praticas e a presença da disciplina na escola por sua contribuição na formação do caráter dos alunos, na formação de seus afetos. No entanto, alguns discursos desses educadores, os quais são decorrentes do caráter funcionalista do processo de educação adotado pela área preconizam que, "ao praticar jogos e esportes as crianças e adolescentes aprenderão a perder e a ganhar, aprenderão respeitar regras e lidar com suas emoçôes".

O entendimento que geralmente se transmite com esta afirmação é de que a simples prática de jogos ou de esporte, tal como um "passe de mágica", fosse capaz de introjetar valores morais, ou ainda, auxiliar no reconhecimento dos sentimentos, favorecendo a construção da afetividade. Assim como Bracht (1997), consideramos que esta concepção funcionalista arraigada precisa ser superada, a fim de levarmos efetivamente em consideraçáo o desenvolvimento das dimensôes afetivas dos educandos.

O ensino da Educação Física na escola e a ênfase em sua relação direta e comprometida com a formação do caráter bem como da dimensão afetiva tem sido uma ideia recorrente. Além disso, este entendimento ganha força na atualidade, principalmente por estarmos diante de um cenário social em que os valores morais estấo passando por questionamentos, redefiniçóes e crise, decorrente das crises em outros segmentos sociais (LA TAILLE e MENIN, 2009; LA TAILLE, 2006, 2009). Logo, cabe indagar: o que significa no ensino a ser oportunizado pela disciplina de Educaçấo Física, ter a finalidade de favorecer a afetividade, visando ao desenvolvimento moral?

Diante da problemática exposta, o artigo tem como objetivo principal apresentar estudos que explicitam pressupostos teóricos construtivistas em relação ao desenvolvimento da afetividade de estudantes, buscando tecer relaçôes entre eles e suas contribuições na construção da afetividade em aulas de Educação Física.

Tendo em vista o objetivo descrito, apresentaremos inicialmente um breve cenário da produção acadêmica sobre a afetividade na Educação Física para em seguida apresentarmos os pressupostos construtivistas que fundamentam açôes pedagógicas relativas à afetividade na escola. Ao final, concentraremo-nos em realizar uma reflexão sobre alguns conteúdos da Educação Física, partindo do pressuposto de que a necessária construção da afetividade implica em considerar a formação da identidade dos alunos, e que, no processo de ensino-aprendizagem, se concretize a problematização e a ressignificação dos valores que os alunos elegem para se representar.

\section{Estudos em Educação Física envolvendo o tema afetividade}

$\mathrm{Na}$ atual legislação brasileira, a Educação Física é componente curricular, contendo um conjunto de conhecimentos que devem ser ensinados na instituição escolar 
(BRASIL, 1996). E, como componente curricular, em articulação e integração com os demais componentes do projeto pedagógico, proporciona aos estudantes experiências que ampliem as possibilidades de açóes coletivas e individuais.

As possibilidades que emergem com a promulgação da Lei de Diretrizes e Bases da Educação Nacional (LDBEN) representam um marco na história da Educação Física na escola, na medida em que permitem distanciá-la dos estigmas que a vinculavam a uma área de atividade de "relevância duvidosa". Esse estigma já vinha sendo denunciado desde a década de 80 por professores e pesquisadores que se propunham a repensar uma nova Educação Física para além do físico tão só (BRACHT, 1999; SOARES, 1992; 1998; SERGIO, 1991; 1996).

Ao considerarmos a Educação Física como matéria escolar, entendemos que seu objetivo principal é promover aos educandos a construção e compreensão de sua motricidade. Como disciplina, possui conteúdos e objetivos próprios que incidem sobre o ser/estar humano na sociedade com suas múltiplas dimensóes, sejam elas físicas, psicológicas, afetivas, culturais, morais ou sociais. Portanto, negar uma dessas dimensōes é negar a humanidade presente em nossas aulas e a humanidade possível de ser construída, reduzindo-a e limitando o campo de saber.

Quando nos dedicamos a verificar a produção de pesquisas sobre a temática da afetividade e suas relaçóes com a Educaçáo Física na escola, veremos que ela comporta uma amplitude de investigaçóes. As pesquisas se diferem em seus objetos de estudos, referenciais teóricos de sustentação, instrumentos de investigação e análise, revelando-nos uma diversidade de entendimentos conceituais que têm sido associados à ideia do que seja tratar a afetividade nas aulas, nos cursos de formaçáo de professores e de como sentir/ avaliar a presença desta nas relaçóes interpessoais que ocorrem no cotidiano escolar.

É possível perceber uma tendência de proposiçôes de estudos e pesquisas em direção aos princípios didáticos que levam em consideração o sujeito em sua totalidade, bem como a afirmaçáo da necessidade de superar a concepçáo biologicista da área que prioriza apenas os aspectos motores.

Nesta linha propositiva, Monteiro (2006), Loberto (2005), Querido (2007), fundamentados na concepção Walloniana, se dedicaram a pesquisar sobre a afetividade em aulas de Educaçáo Física.

Em seus estudos, Oliveira (2005) considerou as possibilidades e limitaçóes de uma proposta que visa contribuir para a formaçáo de professores de Educação Física que considerem a afetividade em suas práticas pedagógicas.

A pesquisa feita por Malaco (2004), envolvendo a formação de professores, aponta que os mesmos têm dificuldades em lidar com suas próprias emoçóes e as de seus alunos. Defende que o futuro professor necessita entender a dimensão da afetividade e saber intervir adequadamente no processo educativo.

A preocupação em estabelecer uma interlocução entre Educação Física e Psicologia é destacada por Moreira (2011). Fundamentando-se na psicologia construtivista 
semiótico-cultural a autora afirma que pouca atenção tem sido dada ao desenvolvimento afetivo da pessoa.

Em relação à abordagem fenomenológica Antunes (1993), estudou as manifestaçôes da emoção vivida no processo de aprendizagem da Educação Física, bem como o trabalho de Hirama (2002), que investigou a manifestação das emoçôes nas aulas de Educação Física.

Andreazza (1997), partindo de referências como Maslow e Piaget, pesquisou a influência do nível de afetividade entre professor e aluno no rendimento escolar.

Segundo os estudos de Shigunov (1991), as atitudes das pessoas são manifestaçóes de seus estados emocionais, portanto, os comportamentos dos professores contribuirão em grande parte na estruturação da personalidade da criança.

A pesquisa realizada por Erbs (2007), teve como eixo-orientador o movimento humano e as relaçóes emocionais-afetivas entre professores e alunos. Nesta pesquisa identificou-se uma aproximação entre a teoria do "se-movimentar" de Elenor Kunz e a "educação dialógica" de Paulo Freire.

De um modo geral, no conjunto de investigaçóes realizadas destacam-se as relaçôes afetivas entre professores e alunos e a preocupação com a formação de professores que considere dimensão afetiva do ser humano.

Em relação aos pressupostos do construtivismo piagetiano não encontramos estudos que discutem a intervenção dos professores e futuros professores de Educação Física, tampouco discussóes de teor bibliográfico que comporte a presente teoria. Estudos como os de Tognetta (2003, 2009), e Tognetta et al (2011), envolvendo o tema da afetividade na educação nos auxiliam a repensar a temática no âmbito das aulas de Educação Física. Nesse sentido, nossa intenção é contribuir com a discussão iniciada pelos estudos anteriores, trazendo os princípios da Epistemologia Genética para esta temática.

\section{Estudos piagetianos no desenvolvimento moral: a cognição e a afetividade como invariantes funcionais}

Defendemos que também é objetivo da educação escolarizada a formação da ética e da moral. Ao nos referir às terminologias moral e ética, cabe destacar as diferenças entre ambas.

Para La Taille (2006), entende-se por moral um conjunto de regras que nos direcionam à maneira de agir nas diversas situaçóes para o bem comum. Para a ação ser moral, depende da dimensão intelectual do ser humano, logo, dos conhecimentos e dos instrumentos fornecidos pela razáo. A moral diz respeito a algo que a pessoa deve conhecer (regras, princípios e valores).

Nos estudos realizados por Piaget (1932/1977), fica evidente que para ser moral o ser humano depende das operaçôes mentais que são feitas, da conquista de um pensamento reversível e recíproco. 
As dimensóes afetivas (o querer agir moral) representam o outro invariante psicológico que explica as condutas morais além da dimensão intelectual acima citada. As pesquisas recentes em psicologia moral contribuem com estudos que revelam a necessidade de que a regra (moral) a ser seguida tenha sentido para quem a faz, que a açáo a ser escolhida encontre lugar no projeto de vida que cada pessoa elege.

Neste momento, nos aproximamos do conceito de ética, o que nos remete ao projeto de "vida boa" e com sentido. A pergunta fundadora da ética é: que vida viver? Quem eu quero ser? (LA TAILLE, 2006).

A ética aproxima-se da dimensão afetiva constituinte do sujeito, pois de forma geral, as pessoas conhecem as regras que devem seguir, porém, em muitas ocasiốes não as seguem. Cabe lembrar que o acúmulo de conhecimentos não basta para agir moralmente, pois a ação depende ainda da imagem que projetamos de nós mesmos, ou seja, depende do sentido que atribuímos a certas açóes (TOGNETTA, 2009).

Assim, "a formação de valores morais ou éticos depende de algo além da tomada de consciência do dever: depende de uma motivação interna para a ação, chamada de sentimento"(TOGNETTA, 2009, p.17). A afetividade é a energia que nos move a agir em direção a nós mesmos e ao meio que nos circunda, é a fonte energética que nos leva a eleger algo com maior ou menor valor (PIAGET, 1952/1994).

Outro conceito importante para entendermos as dimensôes afetivas que compóem a construção da moral é o conceito de valor. Qualquer objeto, seja de natureza objetiva e concreta ou subjetiva (ideias, planos), desde que revestido de afetividade, passa a ser um valor para o sujeito.

Vale destacar que os valores construídos podem ser morais (respeito, justiça, solidariedade, entre outros) ou náo morais (sucesso, riqueza, beleza, etc.).

Desde que nascemos, a afetividade faz-se presente nas interaçóes estabelecidas com o meio circundante, na busca por conhecer e dar sentido ao mundo. Essa energia que investimos nos outros e em nós mesmos leva-nos a buscar uma boa imagem de nós (ou expansão de si), algo que nos identifique e nos faça sentir-se realizados. A tendência à expansão de si mesmo, enquanto busca da vida boa e com sentido, é considerada um processo psicológico universal, ou seja, almejado por todo ser humano (LA TAILLE, 2006).

Explicando mais detalhadamente, encontramos que o "eu" é definido como o "conjunto das representaçóes de si" (LA TAILLE, 2002). Tais representaçóes são conceitos e imagens que cada um possui de si mesmo, construídas nas interaçóes, sendo sempre valorativas, ou seja, avaliadas pela própria pessoa de forma positiva ou negativa.

Outro fator a ser considerado é a ânsia dos seres humanos pelas representaçóes de si com valor positivo. Estamos ativamente assimilando e integrando valores à nossa identidade, podendo ser morais ou não morais conforme mencionado. Tais valores podem ainda ocupar um lugar periférico ou central na identidade dos indivíduos (LA TAILLE, 2002; VINHA, 2000; ARAÚJO, 1999). 
Quando os valores morais estão presentes e se encontram no centro das representaçôes de si, pode-se dizer que essa pessoa possui o sentimento de autorrespeito. Quando os valores morais estão presentes, mas se encontram na periferia do "eu", a situação é menos favorável ao pensar e agir moral, porque há valores preponderantes sobre eles. Nesse caso, fala-se em autoestima e não autorrespeito.

Assim, aquilo que uma pessoa pensa e julga e a maneira como se conduz na vida depende de sua hierarquia de valores e do lugar que ocupam na identidade do sujeito, depende ainda do que valoriza e em que investe seus afetos.

Tognetta (2009) afirma que, para ser contemplada a perspectiva ética de uma "vida boa" e com sentido, é importante que o ser humano sinta-se valorizado para que possa valorizar o outro. Nas palavras de La Taille, "respeita a moral quem, ao fazê-lo, respeita a si próprio" (2006, p. 56). Dessa forma, aquele que possui autorrespeito age de forma moral e respeita o próximo.

Diante de tais discussóes, temos que, para se ensinar visando à afetividade na escola segundo os pressupostos piagetianos, é necessário ter claro que falar de afetividade é falar da construçấo do autorrespeito. Esse, por sua vez, é conquistado paulatinamente quando há condiçóes para que o educando se conheça, quando é valorizado, ouvido por outros e quando expressa o que sente e pensa (TOGNETTA, 2009). É somente ao se conhecer que o sujeito poderá atribuir-se valor. $\mathrm{O}$ conhecimento de si permite-lhe controlar a energia (afetividade) que o move a agir. Para os autores mencionados, esse controle é importante para a construção e manutenção de relacionamentos saudáveis.

Priorizar um trabalho com as virtudes morais abre possibilidades para que os alunos reflitam sobre as qualidades do ser humano que promovam uma "vida boa" e com sentido. E nesse processo reflexivo, realizem açôes de abstraçóes que ajudem considerar a importância dessa "vida boa", com sentido para si e para os outros.

\section{Construção do autorrespeito nas aulas de Educação Física: tecendo relações a partir dos conteúdos}

Priorizar em um artigo as questóes afetivas, revalidando a necessidade de escrever sobre a construção do autorrespeito, não significa abrir mão dos conteúdos da Educação Física no sentido de psicologizar a educação ou relativizar as diversas possibilidades almejadas, organizadas e sistematizadas junto aos alunos.

Apresentaremos a seguir parte de um trabalho de organização curricular para a Educação Física, elaborada por um grupo de professores e organizado por Palma, Oliveira e Palma $(2008,2010)$, no intuito de apontar algumas possibilidades de se conceder um olhar especial para a afetividade e para as virtudes morais.

A escolha por esta obra justifica-se na medida em que os conteúdos que podem ser ensinados nas aulas de Educação Física foram ampliados, redefinidos e organizados didaticamente em núcleos de concentração, proprocionando maior complexidade. Nesse sentido, os núcleos de concentração a serem ensinados na Educação Básica, Educação de Jovens e Adultos e Educação Especial são nomeados como: o movimento e a corporei- 
dade; o movimento e os jogos; o movimento e os esportes; o movimento em expressão e ritmo; o movimento e a saúde.

Reescrevemos os objetivos de três deles na tentativa de sintetizá-los, buscando tecer relaçóes entre estes e a construçáo progressiva do respeito por si e por outros.

O primeiro núcleo a ser exemplificado, denominado "o movimento e a corporeidade", objetiva-se organizar situaçóes de vivências corporais e estudos das estruturas capacitativas e perceptivas (força, velocidade, lateralidade, resistência, entre outros) que possibilitem a compreensão de ser um corpo em movimento em constante interaçáo com objetos e pessoas.

Nas aulas sobre a lateralidade, por exemplo, há espaços para pensarmos sobre as seguintes questóes: porque tenho dificuldade ou facilidade e desempenho para executar determinados movimentos com certos lados corporais e não com outros? Por que em certas épocas se castigavam e discriminavam os canhotos? Quais as justificativas para tal discriminação? Será que estas pessoas são discriminadas ainda hoje?.

Estes questionamentos nos conduzem a refletir em como se sentem as pessoas em suas diferenças, no caso, a dominância lateral, quais suas dificuldades ao utilizar certos objetos e utensílios feitos especialmente para os destros e ampliar o debate pesquisando outras formas de discriminação sociais implícitas e explícitas, sentidas e percebidas. As propostas para se vivenciarem açóes motoras que evidenciem a coordenação motora, ou maiores níveis de força corporal, ou ainda que exijam as capacidades físicas de agilidade e velocidade podem gerar insegurança por parte dos alunos, principalmente se a atividade envolver a competiçáo, fator desencadeador de conflitos intrapessoais e interpessoais. A construção da descentração cognitiva e afetiva é um caminho viável quando se convida os alunos a perceberem as dificuldades alheias diante de discriminaçóes que vão sendo naturalizadas, as causas das mesmas, os sentimentos diversos que os colegas podem sentir em situaçóes variadas e mesmo corriqueiras da vida.

Nestas aulas, tais propostas e as decorrentes dificuldades encontradas podem favorecer o desenvolvimento do domínio de si mesmo, reconhecimento das próprias possibilidades corporais, além da tomada de consciência dos esquemas motores envolvidos, dos sentimentos gerados e dos valores implícitos. Isso ocorre quando o professor favorece aos alunos momentos de reflexão e tirem conclusóes sobre: Quais formas diferentes de me movimentar experenciei? Quais os sentimentos gerados diante das novas propostas? Quais dificuldades encontrei e superei? Como posso auxiliar outras pessoas nesta atividade? A sociedade atribui valores diferentes ao desenvolvimento das diversas capacidades físicas?.

É importante o professor oportunizar aos alunos momentos para conhecerem a si mesmos, pensarem naquilo que dedicam seu tempo, aquilo que lhes dão prazer em aprender, as manifestaçóes culturais preferidas e que expressam capacidades físicas diferentes, bem como veiculam modos de ser, agir e pensar plurais com os quais o grupo de alunos convive de maneira mais ou menos harmoniosa em uma sala de aula. Consideramos que, promover a reflexão e abstrações sobre as próprias ações, limites e superações, individuais e coletivas, contrapondo valores, favorecerá o reconhecimento do propósito 
que os move, direcionando-os à conquista do respeito por si e consequentemente à valorização do outro.

Ao propor estratégias diversificadas que exigem níveis crescentes de complexidade de coordenação motora poderão surgir conflitos interpessoais decorrentes de diversas causas: da vergonha do aluno pela exposiçáo, ou pela falta de desenvolvimento das habilidades motoras. Desconfortos que surgem tanto por parte da realizaçáo da ação como da expectativa de se sentir "competente", de manter uma imagem positiva perante os colegas e corresponder aos desafios proporcionados pela atividade. Nestes momentos a imagem que os alunos possuem de si mesmos e perante o grupo estaráo sendo construídas, avaliadas, reafirmadas, reconstruídas.

As dificuldades e expectativas na execução de determinadas ações podem dar lugar às rixas, provocaçôes, sentimentos de raiva, frustração, situaçôes as quais o professor pode intervir de forma a acolher os sentimentos com uma linguagem descritiva, justamente porque as relaçôes com as autoridades são uma das dimensōes a serem tratadas na construçáo do respeito por si, além das relaçóes entre pares e da relaçáo consigo mesmo (TOGNETTA, 2009).

A atitude que promove a construção de valores morais é quando os alunos se atribuem valor, quando estão em relaçôes de confiança, quando sabem que podem expor suas dúvidas, errar, acertar, quando seus sentimentos e açôes são acolhidos sem serem julgados, quando há chances para expressar sentimentos. Todas as situaçóes que geram desconforto podem ser alvos de reflexão.

O docente pode suscitar as seguintes questóes para que sejam discutidas, analisadas, interpretadas e concluídas no coletivo dos alunos: Como podemos agir com respeito nesta situaçãa? Quais sentimentos provocam os desafios motores vivenciados? Como podemos superar tais dificuldades e problemas? Como podemos formar os grupos sem excluir?. Entendemos que todas estas questôes são momentos que podem levar a aprendizagem do reconhecimento dos sentimentos que movem os alunos, da energia que os levam a interagir de forma mais agressiva, passiva ou assertiva.

A construção do autorrespeito é um caminho que tanto os estudantes que excluem como os que são excluídos devem trilhar. Assim, para os alunos que excluem, devemos perguntar, quais valores eles precisam construir? Qual imagem de si mesmo querem manter?.

O professor contribui para a construção do respeito por si mesmo quando proporcionar aos alunos oportunidades de tomarem consciência das causas e consequências de suas açóes para o grupo e para a sociedade, promover a antecipaçấo de novas formas de agir a fim de que os alunos possam construir formas mais equilibradas de se relacionar.

Ao reconhecer as próprias qualidades e as dificuldades no estudo das capacidades físicas podemos também estudar os meios de superá-las sem sentir-se inferiorizados. Os desafios lançados devem ser vistos pelos alunos como oportunidades de se conhecerem enquanto corporeidade viva, irrepetível e principalmente entender-se como um sujeito inacabado, tratando as dificuldades como situaçōes contornáveis e que nos move a construir uma identidade. 
O segundo núcleo que iremos abordar inclui dois conteúdos muito próximos. Os núcleos intitulados o movimento e os jogos e o movimento e os esportes sáo diferentes, apesar de articulados. Portanto, optamos por demonstrar a possibilidade do trato com a afetividade em um único texto por ambos apresentarem objetivos próximos. Esses se circunscrevem em oportunizar o estudo e a vivência das manifestaçóes lúdicas e esportivas como integrantes da cultura motora, contribuindo no processo de construçáo da motricidade.

Ao estudarmos os personagens representativos das diversas modalidades esportivas encontraremos virtudes morais e não morais a serem exploradas, debatidas e ressignificadas pelos educandos.

A construção e a integração progressivas de virtudes morais podem ser contempladas indiretamente por meio da apresentação e reflexão dos projetos de vida que guiam os ídolos presentes no cenário esportivo (LA TAILLE, 2009). Assim, além dos aspectos técnicos e táticos dos jogos e esportes, outras questôes podem ser destacadas nas aulas, tais como: Quem são os ídolos que pertencem ao mundo esportivo? Quais atitudes destas pessoas são admiradas pelo público? Todos da turma concordam com estes valores? Quais atitudes são criticadas? Como a mídia retrata as celebridades? Que tipo de influência isto tem em nosso modo de vida?.

Podemos ainda pesquisar e contrapor outros momentos históricos entrevistando os pais, avós, professores, indagando quais foram os ídolos de outras décadas, investigando quais atitudes e virtudes eram louváveis, levando à reflexáo do que mudou ou náo mudou com o tempo e o que os estudantes pensam deste tema.

Os eventos que acontecem nas torcidas organizadas são oportunidades para uma reflexão sistematizada sobre os valores morais e não morais. Caberá ao docente possibilitar a expressão das idéias dos alunos por meio do debate, desenho, escrita, e formas de expressão artística. Estas são maneiras de suscitar as crianças a pensarem sobre as atitudes contrárias à moral. Tal fato, segundo Tognetta $(2003,2009)$, pode indicar ao próprio grupo os valores que precisam ser construídos.

Nas aulas em que os jogos e esportes se encontram presentes, certamente muitos sentimentos divergentes emergirão, pois nestes momentos há situaçóes de disputas e confrontos diretamente. É no exercício de repensar a condição de "agredidos e agressores" que os alunos terão oportunidades de tomarem consciência dos sentimentos que os movem a agir, reconhecer seus próprios valores, contraporem com os de outros, podendo ressignificar suas próprias relaçôes.

Os sentimentos que surgem durante as disputas em aulas podem ser fonte de reflexão sobre valores e virtudes morais. Pensar sobre a polidez, amizade, respeito, justiça, tolerância e honestidade, coloca os estudantes em constantes situaçóes de desequilíbrios e equilibraçóes quando se considera suas relaçóes de vivência e convivência consigo e com outros. Nas aulas, é importante momentos para pensar em como um grupo pode celebrar a vitória sem menosprezar, sobre a vantagem de se ganhar uma partida de forma ilícita, sobre a necessidade que os alunos têm em jogar para se vingar, exibir, para participar do grupo dos "vencedores" e náo ser associado ao grupo de "perdedores". 
Neste sentido, uma boa oportunidade no estudo destes conteúdos é utilizarse dos jogos de expressão de sentimentos como os propostos por Tognetta $(2003,2009)$, adaptando-os às situaçôes específicas que ocorrem nas aulas de Educação Física. São momentos em que os alunos irão refletir sobre as representaçóes que têm de si e sobre as virtudes morais a serem projetadas enquanto plano de "vida boa".

Nestes jogos há situaçôes em que os alunos devem entrar em concordância, fatos para serem debatidos ou ainda frases que devem ser completadas, conduzindo os alunos a refletirem sobre os sentimentos e ações.

As frases e situaçôes a serem completadas, debatidas pelos alunos poderiam ser, por exemplo: "Quando vejo o ídolo "x" ele me inspira/eu admiro; Quando há violência na torcida isto me causa; Quando um time humilha outro no campo eu penso/sinto que; Quando meu time ganha no jogo de forma desonesta eu me sinto; Uma atitude que eu observo durante uma partida que me deixa feliz é; Quando jogamos na escola um fato que me deixa irado/indignado é; Quando eu tenho uma boa performance na partida isso me faz sentir/pensar; Quando meu colega joga muito bem uma partida eu; Quando o professor propõe um esporte/jogo que eu não sei eu; A melhor maneira de resolver problemas no time é".

Os jogos de expressão de sentimentos conduzem os alunos a pensarem sobre os sentimentos que movem as pessoas a agir e interagir, colocando em evidência um conteúdo moral a ser agregado. Nestes momentos os alunos teráo oportunidade de constatar que uma mesma situaçáo pode comportar variadas interpretaçóes, contribuindo para ampliar o leque de virtudes morais a serem investidas.

Por fim, ressaltamos que segundo os pressupostos do construtivismo não serão as liçôes de moral dadas durante as partidas de futebol, bola queimada, bets, basquetebol, manifestação artística entre outros conteúdos que farâo com que os valores morais sejam construídos, mas o próprio processo de análise, discussão e abstração dos mesmos. Este processo envolve estudar nas aulas de Educação Física as manifestaçôes culturais, praticando-as, reelaborando-as e problematizando os valores a ela associados, analisando como a mídia, a família, a cultura escolar os retratam e os hierarquizam, refletindo ainda como todo este contexto interfere em nosso modo de agregar e aspirar a determinados valores e náo outros. Intervençóes que se orientem no sentido de ampliar o leque de virtudes para que os discentes tenham opçôes de escolhas para se representar.

Cabe ao professor reconhecer que, na construção e expressão de sua motricidade, os alunos sempre estarão buscando atribuir-se valor, ou seja, construir representaçóes positivas de si mesmo rumo à expansão própria. É importante que o docente reflita junto ao grupo sobre quais valores morais estaráo sendo escolhidos e desenvolvidos para representarem a si mesmos. Por fim, refletir sobre a nossa própria corporeidade e na de nossos pares implica descentração e inserção do outro em nossas açóes e escolhas, remetendo-nos a um projeto de vida ética.

\section{Conclusão}

Garantir o lado afetivo nas aulas de Educação Física pressupóe repensar sobre questóes epistemológicas e ontológicas da relação pedagógica. Explicitamos que ensinar 
favorecendo a afetividade na escola segundo os pressupostos construtivistas implica promover a tomada de consciência das representaçóes que o sujeito tem de si e do grupo, bem como de quais projetos de vida relacionam-se a tais representaçóes. Essa açáo pode ser realizada de forma indireta nas aulas por meio da reflexão das virtudes morais. Neste sentido, apresentamos alguns exemplos em que as virtudes morais e as representaçóes que os alunos possuem, individual e coletivamente, são tematizadas nas aulas.

Evidenciamos a importância do professor de Educação Física desenvolver um trabalho com a identidade dos alunos ao perceber a necessidade que eles possuem de se sentirem valorizados, possibilitando assim, a construção do autorrespeito.

Entendemos que, ao tratar com o conhecimento que provém do jogo, do esporte, da luta, da dança, da ginástica, da integração com os temas saúde, trabalho, ética, dentre outros, o docente terá amplas possibilidades de resgatar valores cujos conteúdos sáo morais, a fim de que sejam assimilados pelos educandos. Esses, enquanto sujeitos ativos na construção do conhecimento e de seus próprios valores poderão investir seus afetos, tornando-se valor para eles.

Identificamos que há possibilidade de construção do autorrespeito nas aulas principalmente quando o educador tem fundamentos teóricos consistentes e um olhar atento para tal temática, entendendo o ser humano como um sujeito inacabado, o qual, no esforço de se adaptar e se sentir valor "no" e "para" o mundo, buscará responder questóes como: De que maneira devo agir? Que vida quero viver? Quem eu quero ser?.

\section{Referências}

ANDREAZZA, J. Uma abordagem da afetividade entre professor e aluno nas aulas de educação física em escola de $2^{\circ}$ grau. Dissertação (Mestrado), Universidade Federal de Santa Maria, Santa Maria, 1997.97 p.

ANTUNES, R. C. F. S. As manifestações da emoção vivida no processo de aprendizagem da educação física escolar: totalidade ininterrupta de troca e construção de experiênciashumanas. Dissertação (Mestrado em Educação Física), Faculdade de Educação Física, Universidade Estadual de Campinas, Campinas,1993.146 p.

ARAÚJO, U. F. Escola, democracia e a construção de personalidades morais. Educação e Pesquisa. São Paulo, Faculdade de Educação/USP, v. 26, n.2, p. 91-107, jul./dez., 2000.

BRACHT, V. Educação física e aprendizagem social. 2. ed. Porto Alegre: Magister, 1997.

BRACHT, V. A constituição das teorias pedagógicas da Educação Física. Revista Brasileira de Ciência do Esporte. Campinas, n. 01, p. 15-53, 1999.

BRASIL. Lei de Diretrizes e Bases da Educação Nacional. Lei n. 9.394. Ministério da Educação Brasília, DF, 1996.

ERBS, C. As relações afetivas nas aulas de Educação Física escolar: espaço de encontros e reencontros.Dissertaçãoo (Mestrado), Universidade Federal de Santa Catarina, 2007.71 p.

HIRAMA, E. P. As emoções na Educação Física Escolar. Tese (Doutorado em Educação Física), Departamento de Departamento de Educação Motora, Faculdade de Educação Física, Campinas, 2002. 287 p.

LA TAILLE, Y. Vergonha, a ferida moral. Petrópolis, Rio de Janeiro, Vozes, 2002. 
LA TAILLE, Y. Moral e ética: dimensões intelectuais e afetivas. Porto Alegre, Artmed, 2006.

LA TAILLE, Y. Formação Ética. Do tédio ao respeito de si. Porto Alegre, Artmed, 2009.

LA TAILLE, Y; MENIN, M.S.M. (Org.). Crise de valores ou valores em crise? Porto Alegre, Artmed, 2009.

LOBERTO, T. S. O papel da afetividade no processo ensino-aprendizagem segundo futuros professores de Educação Física. Dissertação (Mestrado em Educação: Psicologia da Educação), Pontifícia Universidade Católica de São Paulo, 2005.153 p.

MALACO, L. H. A formação de educadores e a afetividade dos estagiários de Educação Física em relação à prática docente. Tese (Doutorado em Psicologia: Psicologia Social), Pontifícia Universidade Católica de São Paulo, 2004. 150 p.

MACEDO, L. Os sujeitos de Piaget e sua educação. In Anais XXV Encontro Nacional de Professores do PROEPRE - Escola, torna-te o que es! UNICAMP FE 2012, Campinas.

MONTEIRO; M. D. As manifestações afetivas nas aulas de educação física: análise de uma classe de $3^{\text {a }}$ série do ensino fundamental na perspectiva de Henri Wallon. Dissertação (Mestrado em Educação: Psicologia da Educação), Pontifícia Universidade Católica de São Paulo, $2006.121 \mathrm{p}$.

MOREIRA, C. R. P. Educação Física e Psicologia: em busca de novos diálogos. Doutorado. Tese (Doutorado em Psicologia: Psicologia Experimental), Universidade de São Paulo, 2011.159 p.

OLIVEIRA, G. K. Afetividade e prática pedagógica: uma proposta desenvolvida em um curso de formação de professores de Educação Física. Tese (Doutorado em Educação: Psicologia da Educação), Pontifícia Universidade Católica de São Paulo, 2005.

PALMA, A. P. T. V. P.; OLIVEIRA, A. A. B.; PALMA, J.A.V. Educação Física e a organização curricular: educação infantil e ensino fundamental. Londrina, EDUEL, 2008.

PALMA, A. P. T. V. P.; OLIVEIRA, A. A. B.; PALMA, J.A.V. Educação Física e a organização curricular: educação infantil e ensino fundamental e ensino médio. Londrina, EDUEL, 2010.

PIAGET, J. O julgamento moral na criança. São Paulo, Mestre Jou, 1932/1977.

PIAGET,J. Las relaciones entre la inteligencia y la afectividad en el desarrollo mental del ninõ. In: DELAHANTY, G. PERRËS (Comp). Piaget y el psicoanálisis. México: UniversidadeAutonoma Metropolitana, 1952/1994.

SHIGUNOV, V. A relação pedagógica em Educação Física: influência dos comportamentos de afetividade e instrução dos professores no grau de satisfação dos alunos. Tese (Doutorado em Motricidade Humana),Universidade Técnica de Lisboa, Lisboa, 1991.

QUERIDO, A. F. F. (2007). Afetividade e formação em Educação Física: um estudo com professores formadores. Dissertação (Mestrado em Educação: Psicologia da Educação), Pontifícia Universidade Católica de São Paulo, São Paulo, 2007.135 p.

SERGIO, M. Educação Física ou ciência da motricidade humana? 2aed. Campinas, São Paulo: Papirus, 1991.

SERGIO, M. Epistemologia da motricidade humana. Lisboa. Lisboa : Edições FMH, 1996

SOARES, C. L. et al. Metodologia do ensino de Educação Física. São Paulo, Cortez, 1992.

SOARES, C. L. S. Imagens da educação no corpo: estudo a partir da ginástica francesa no século XIX. Campinas, Autores Associados, 1998. 
TOGNETTA, L.R. P. A construção da solidariedade e a educação do sentimento na escola. Campinas: Editora Mercado de Letras, 2003.

TOGNETTA, L.R.P. A formação da personalidade ética: estratégias de trabalho com afetividade na escola. Campinas, Mercado das Letras, 2009.

TOGNETTA, L.R.P, et all. Formación ética y afectividad: entre lasconcepciones de loseducadores ysugenuinaimportancia. Postconvencionales. Escuela de estudios políticos y administrativos, Universidad Central de Venezuela, n. 3, p. 7-25, março, 2011.

VINHA, T. P. O educador e a moralidade infantil numa visão construtivista. Campinas: Mercado da Letras, 2000.

* Professora da Rede Municipal de Londrina. Doutora em Educação pela Universidade Estadual Paulista Júlio de Mesquita Filho (UNESP).

** Docente do curso de Educação Física - licenciatura e membro do Laboratório de Pesquisa em Educação Física - LaPEF”.

\section{Correspondência}

Luana Cristine Franzini de Conti - Prefeitura Municipal de Londrina, Secretaria Municipal de Educação. Rua Duque de Caxias 635, Jardim Mazzei, CEP: 86015901 - Londrina, Paraná, Brasil.

E-mail: luana.cristine.franzini@gmail.com - angpalma@uel.br

Recebido em 26 de junho de 2014

Aprovado em 20 de novembro de 2015 
